\title{
Analisis Karakteristik Strategi Konten E-commerce Indonesia menggunakan Pendekatan Social Network Analysis untuk Market Intelligence
}

\author{
Oleh: \\ Afrilia Utami ${ }^{1}$, Andry Alamsyah ${ }^{2}$ \\ 1,2 School of Economics and Business, Telkom University, Bandung Indonesia \\ 19afrilia.utami@gmail.com, ${ }^{2}$ andrya@ telkomuniversity.ac.id
}

\begin{abstract}
ABSTRAK
Peningkatan penetrasi pengguna internet di Indonesia telah mentransformasikan pasar ke dalam ekonomi digital yang berdampak pada tingginya daya kompetisi antara e-commerce. Ketersediaan online data dapat memberikan strategi bagi bisnis untuk menemukan cara baru dalam memahami perilaku pasar. Kami menganalisa karakteristik konten e-commerce. Penelitian ini mengukur dan membandingkan sifat analisis jaringan sosial dan jenis konten di antara dua e-commerce Bukalapak dan Lazada di halaman Facebook. Penelitian ini dapat memberikan wawasan tentang apa yang penting dalam memahami pasar dengan mengidentifikasi jenis karakteristik konten di antara $e$ commerce dalam kampanye pemasaran media sosial dan ukuran pasar yang ditunjukkan oleh nilai keterlibatan konten mereka dan percakapan komunitas masing-masing jaringan sosial dalam $e$ commerce.
\end{abstract}

Kata Kunci: E-commerce, Social Network Analysis, Bukalapak, Lazada, Facebook.

\section{ABSTRACT}

The increasing penetration of internet users in Indonesia has transformed the market into a digital economy that has an impact on the high competitiveness of e-commerce. The availability of online data can provide a strategy for businesses to find new ways to understand market behavior. We analyze the characteristics of e-commerce content. This study measures and compares the analytical nature of social networks and the types of content between two e-commerce Bukalapak and Lazada on the Facebook page. This research can provide insight into what is important in understanding the market by identifying the types of content characteristics between e-commerce in social media marketing campaigns and market size indicated by the value of their content involvement and community conversations of each social network in e-commerce.

Key Words: E-commerce, Social Network Analysis, Bukalapak, Lazada, Facebook.

\section{I.PENDAHULUAN}

Pertumbuhan penetrasi pengguna internet di Indonesia merupakan salah satu dampak yang ditimbulkan oleh peningkatan penggunaan teknologi dalam dunia bisnis. Indonesia berada di posisi tiga besar sebagai negara dengan pengguna internet paling aktif di Asia dengan 132.700.000 pada bulan Juni 2017(Stats, 2017). Jumlah eskalasi transaksi online telah mempengaruhi persaingan e-commerce di Indonesia. Upaya untuk tetap kompetitif dengan situs $e$-commerce serupa diukur dengan aktivitas pemasaran intelijen.

Kecerdasan pemasaran merupakan proses pemahaman, analisis, dan penilaian lingkungan internal dan eksternal perusahaan yang terkait dengan pelanggan, pesaing, pasar, dan kemudian menggunakan informasi dan pengetahuan yang didapat untuk mendukung keputusan pemasaran yang terkait dengan perusahaan. Kecerdasan pemasaran menyediakan peta jalan tren terkini dan masa depan dalam preferensi dan kebutuhan pelanggan, peluang pasar dan segmentasi baru, dan pergeseran besar dalam pemasaran dan distribusi untuk 
memperbaiki perencanaan, implementasi, dan pengendalian pemasaran perusahaan (Chern, et.al, 2014).

Salah satu aspek penting dari bisnis e-commerce adalah dalam kampanye sosial online. Pola interaksi melalui teknologi web yang dikenal sebagai jejaring sosial, media sosial atau web 2.0 (Evan, 2010) yang memungkinkan pengguna berinteraksi secara aktif dalam kehidupan sosial. Peningkatan pengguna internet telah meningkatkan aktivitas percakapan jejaring sosial online.

Fenomena persaingan yang tinggi antar perusahaan $e$-commerce. Salah satunya adalah semakin populernya aktivitas belanja online. Lazada dan Blibli termasuk di antara situs $e$ commerce populer yang dikunjungi. Model bisnis mereka adalah kustomer terhadap kustomer, seperti yang dikenal dengan C2C. Upaya untuk tetap kompetitif di antara situs ecommerce serupa diukur dengan strategi karakteristik konten mereka untuk melibatkan pelanggan mereka.

\section{LANDASAN TEORI}

Facebook sebagai platform media sosial utama untuk menganalisis karakteristik konten di antara tiga e-commerce. Jumlah pengguna Facebook di Indonesia mencapai 115 juta pengguna pada 2017 (Reza, 2015). Facebook memiliki fitur yang memudahkan $e$ commerce untuk mempromosikan produk mereka dengan alat pemasaran Facebook. Terdapat berbagai jenis konten misalnyas status, foto, dan video.

Facebook sering dijadikan tempat untuk mengekspresikan pendapat, penyebaran informasi, komentar, dan memungkinkan pengguna internet untuk berkontribusi dalam penyebaran informasi. Adanya media sosial terutama Facebook telah memberikan cara baru untuk menyebarkan informasi secara efektif dan bahkan secara real-time. Selain itu, Facebook menawarkan alat open source yang bisa memudahkan merangkak menyimpan data berharga dengan menggunakan aplikasi Facebook API.

Penelitian ini akan menunjukkan bagaimana suatu organisasi bisnis dapat mengambil data yang diunggah oleh Lazada dan Blili dengan jenis konten mereka dan menganalisisnya dalam konteks kecerdasan pasar untuk mengekstrak wawasan mengenai pasar jaringan mereka. Tujuan dari penelitian ini adalah untuk mengetahui karakteristik konten $e$-commerce di Indonesia pada halaman Facebook agar menjadi informasi berharga bagi perusahaan yang menggunakan analisis jejaring sosial dan untuk mengidentifikasi $e$-commerce yang memiliki tingkat aktivitas tertinggi untuk melibatkan pelanggan dengan membandingkan produktivitas mereka untuk memposting suatu konten.

Jaringan sosial yang dimodelkan dengan teori grafik terdiri dari node dan edge. Node mewakili aktor dan Edge merupakan hubungan antara aktor. Kelebihan model jaringan yang menggunakan teori graph adalah dapat dengan mudah menvisualisasikan data besar. Serta, menyediakan beberapa metrik berdasarkan karakteristik teori graph. Model dan rangkaian metrik disebut dengan Social Network Analysis (SNA) (Zheng, et.al, 2015) (Goldberg, et.al, 2008).

Komunitas diukur dengan pola interaksi alami antara edge. Keputusan apakah edge adalah bagian dari satu komunitas tertentu atau komunitas lainnya bergantung pada algoritma pendeteksian jaringan yang digunakan. Salah satu pengukuran paling canggih untuk 
mendeteksi komunitas adalah Modularitas. Dalam prakteknya, ada banyak kemungkinan subkelompok di dalam suatu komunitas.

\section{METODE PENELITIAN}

\subsection{Metrics}

Kami menggunakan enam unit pengukuran untuk membandingkan dua jaringan yang diobservasi:

3.1.1. Average Degree adalah rata-rata koneksi semua node dengan masing-masing node. Tingkat rata-rata yang lebih tinggi berarti jaringan yang terbangun memiliki tingkat kepadatan yang baik dan meningkatkan probabilitas jalur pintas di antara node/aktor (Goldberg, et.al, 2008).

3.1.2. Network Density didefinisikan oleh rasio jumlah sebenarnya dari tepi dengan jarak maksimum tepi. Kepadatan bisa dikatakan juga sebagai ukuran seberapa dekat hubungan antara node dalam jaringan (Wasserman, 1998). Rumus untuk menghitung kerapatan jaringan adalah:

$$
\Delta=\frac{L}{g(g-1)}
$$

$\Delta$ adalah nilai density, $L$ merupakan actual relationship, $g$ adalah network size (Wasserman dan Faust, 1998).

3.1.3. Average Path Length didefinisikan sebagai rata-rata jarak sepanjang jalur terpendek untuk semua relasi node dalam jaringan. Jarak yang lebih kecil mereprentasikan efisiensi informasi. Di media sosial, rata-rata panjang jalan digunakan sebagai jumlah rata-rata akun atau nodus tertentu

$$
\langle d\rangle=\frac{1}{N(N-1)} \sum_{i, j=1, N} d_{i, j}
$$

$<\mathrm{d}>$ adalah average path length value, $\mathrm{N}$ adalah jumlah node, $\mathrm{d}_{1, \mathrm{j}}$ adalah jarak terdekat node i dan node j (Barabasi, 2012).

3.1.4. Network Diameter didefinisikan sebagai jarak terjauh dari semua jalur yang dihitung dalam jaringan. Metrik ini mewakili jarak tempuh terjauh/terburuk yang perlu diambil untuk penyampaian suatu informasi. Jalur maksimum terdekat dalam jaringan. ketika kedua e-commerce dibandingkan, semakin baik jaringan yang memiliki nilai diameter lebih kecil. Rumusnya adalah:

$$
d_{\max }=(i, j)
$$

Berdasarkan persamaan tersebut, dapat diartikan bahwa diameter adalah nilai terbesar dari simpul i ke j. Diameter jaringan yang lebih kecil menunjukkan fenomena "dunia kecil" yang berarti akan lebih mudah bagi node untuk berkomunikasi satu sama lain karena jaraknya pendek (Barabasi, 2012). 
3.1.5. Modularity digunakan untuk mendeteksi komunitas dalam suatu jaringan. Nilai ini menghitung jumlah sebenarnya dari sisi dalam sebuah komunitas dan nilai yang diharapkan dari dua node dalam jaringan acak jatuh ke dalam komunitas yang sama (Wasserman dan Faust, 1998). Metrik tersebut mirip heuristik probabilistik generik saat menentukan apakah sebuah simpul adalah anggota masyarakat atau tidak.

$$
Q=\frac{1}{2 m} \sum_{i j}\left[A_{i j}-\frac{k_{i} k_{j}}{2 m}\right] \delta_{s_{i}, s_{j}}
$$

$\mathrm{Q}$ adalah nilai modularity, $\mathrm{m}$ merupakan jumlah edge, $\mathrm{A}_{\mathrm{ij}}$ merupakan the actual number of edges antara $i$ and $j, k_{i} k_{j}=$ expected number, $\delta_{s_{i}, s_{j}}$ is Kronecker delta (Barabasi, 2012)

3.1.6. Weakly Connected component adalah grafik yang tidak memperhatikan arah adalah subgraf di mana dua simpul dihubungkan satu sama lain oleh jalur, dan yang terhubung ke simpul tambahan manapun di supergraf. Semakin kecil nilai Connect Component semakin baik karena jaringan tidak terpecah.

\subsection{Nilai Engagement}

Untuk mengukur interaksi sosial, kami mengusulkan sebuah metrik yang disebut nilai keterlibatan, berdasarkan aktivitas pengguna, yang merupakan bagian dari keterlibatan dalam jaringan (Seddon, et.al, 2008). Ada tiga jenis interaksi antara pengguna dan posting di Facebook; komentar, sharing, dan reaksi. Berdasarkan bagaimana Facebook bekerja, semakin banyak pengguna berkomentar, berbagi, dan bereaksi, sebuah posting akan meningkatkan kemungkinan bahwa panci tersebut akan menyebar melalui garis waktu pengguna Facebook, sehingga menghasilkan lebih banyak percakapan. Ini mendefinisikan nilai engagement. Rumusnya adalah:

$$
E v=\sum c_{i}+s_{i}+r_{i}(1)
$$

$E v$ adalah nilai post engement, $c_{i}$ merupakan jumlah komen, $s_{i}$ merupakan jumlah share, dan $r_{i}$ merupakan jumlah dari reactions.

\section{PEMBAHASAN}

Data yang dikumpulkan di halaman Facebook Lazada dan Blili. Dalam kurun waktu satu tahun dimulai bulan 1 September 2016 sampai 30 September 2017. Halaman Lazada per Januari 2018 memiliki 21.652.462 fans, sedangkan halaman Blibli memiliki 6.909.803 fans. Jaringan posting dan pengguna Lazada terdiri dari 634.316 nodes dan 824.281 edges, sedangkan jaringan Blibli terdiri dari 654.520 nodes dan 1.408 .012 edges.

Penelitian ini menggunakan NetworkX untuk menghitung metrik dan Gephi untuk memvisualisasikan jaringan. Namun, karena data berskala besar, kami membatasi perbandingan kami hanya dengan 8 metrik properti jaringan; Size of network of likes, number of node, number of edge, Average degree, Network Density, Modularitas, dan Connected Component. Hasil perhitungan ditunjukkan pada Tabel 4.1 dan nilai keterlibatan dan jenis karakteristik konten di antara tiga jaringan e-commerce ada pada Tabel 4.2. Gambar 4.1 dan Gambar 4.2 menunjukkan peta jaringan Lazada dan Bibi menurut jenis posting. 
Dengan jumlah anggota, atau jumlah yang menyukai jaringan Lazada jauh lebih tinggi daripada jaringan Blibli. Namun, Blibi memiliki jumlah node dan edge lebih besar daripada Lazada. Dapat dikatakan meskipun jumlah jaringan fans berukuran lebih kecil, jaringan Blibli menghasilkan lebih banyak percakapan.

Tabel 4.1. Perbandingan SNA matrics

\begin{tabular}{|c|c|c|c|}
\hline No & Metrix & Lazada & Blibli \\
\hline 1 & Size of Likes & 21.652 .467 & 6.909 .803 \\
\hline 2 & $\begin{array}{c}\text { Number of } \\
\text { Node }\end{array}$ & 634.316 & 654.520 \\
\hline 3 & $\begin{array}{c}\text { Number of } \\
\text { Edge }\end{array}$ & 824.381 & 1.408 .012 \\
\hline 4 & $\begin{array}{c}\text { Average } \\
\text { Degree }\end{array}$ & 2,599 & 4,302 \\
\hline 5 & Density & $4,96 \times 10^{-6}$ & $8,09 \times 10^{-6}$ \\
\hline 6 & $\begin{array}{c}\text { Number of } \\
\text { Community }\end{array}$ & 26 & 12 \\
\hline 7 & Modularity & 0.767 & 0.617 \\
\hline 8 & $\begin{array}{c}\text { Connected } \\
\text { Component }\end{array}$ & 1 & 6 \\
\hline
\end{tabular}

Sumber: Data diolah Tim Peneliti

Metrik topologi lainnya adalah Average degree. Ini menunjukkan jumlah link yang menghubungkan node dalam jaringan (Barabasi, 2012). Semakin banyak link yang menghubungkan node berarti semakin baik karena penyebaran informasi akan lebih cepat. Jaringan yang memiliki skor derajat rata-rata tertinggi adalah Blibli kemudian diikuti oleh Lazada. Ini berarti lebih banyak posting atau lebih banyak komentar pengguna yang dijawab/dibagikan/disukai oleh anggota lainnya, sehingga menciptakan koneksi yang lebih baru.

Semakin besar nilai density jaringan semakin baik karena berarti pelaku dalam jaringan lebih terhubung. Dari tiga e-commerce tersebut, yang memiliki nilai density terbesar adalah Blibli yang kemudian diikuti Lazada. Modularitas mengukur kekuatan kelompok dalam jaringan. Semakin tinggi nilai modularitas berarti semakin solid dan kuatnya kelompok dalam jaringan (Newman, 2012). Nilai modularitas tertinggi adalah Lazada diikuti oleh Blibli. Penelitian sebelumnya menyatakan bahwa nilai modularitas tinggi mengindikasikan struktur komunitas yang baik.

Connexcted component adalah "potongan" terpisah dari grafik sehingga tidak ada hubungan antara bagian-bagiannya. Dari ketiga jaringan tersebut, Lazada memiliki nilai lebih kecil dari komponen yang terhubung, diikuti oleh Blibli. Jumlah yang lebih kecil dari komponen yang terhubung lebih baik karena ini berarti jaringan tidak terpisah menjadi banyak kelompok kecil. Daya saing di antara tiga nilai properti jaringan e-commerce menunjukkan bahwa anggota jaringan Blibli adalah jaringan komunitas yang paling aktif dalam relasi hubungan di dalam jaringannya. 
Jurnal Manajemen dan Bisnis: Performa Volume XV Nomor 2 September 2018

Tabel 4.2 Karakteristik Konten E-Commerce

\begin{tabular}{|c|c|c|}
\hline Description & Lazada & Blibli \\
\hline $\begin{array}{c}\text { Post Type of } \\
\text { User }\end{array}$ & $99,90 \%$ & $99,91 \%$ \\
\hline $\begin{array}{c}\text { Post Type of } \\
\text { Photo }\end{array}$ & $0,07 \%$ & $0.02 \%$ \\
\hline $\begin{array}{c}\text { Post Type of } \\
\text { Video }\end{array}$ & $0.02 \%$ & $0.6 \%$ \\
\hline $\begin{array}{c}\text { Post Type of } \\
\text { Link }\end{array}$ & $0,01 \%$ & $\begin{array}{c}\text { Link, Link, } \\
\text { Link, Link, } \\
\text { Photo. }\end{array}$ \\
\hline $\begin{array}{c}\text { Post Type of } \\
5 \text { Highest } \\
\text { Engagement } \\
\text { Value }\end{array}$ & $\begin{array}{c}\text { Photo, Video, Video, } \\
\text { Video }\end{array}$ \\
\hline \multicolumn{2}{|c|}{ Sumber: Data diolah Tim Peneliti } \\
\hline
\end{tabular}

Sumber: Data diolah Tim Peneliti

Berdasarkan Tabel 4.2. di antara ketiga jaringan e-commerce yang terdiri dari foto, video, status, dan link. Hal ini seperti yang diharapkan dalam jaringan sosial aktif. Nilai keterlibatan paling utama dari karakteristik konten yang didominasi oleh Lazada adalah foto, Blibli adalah link.

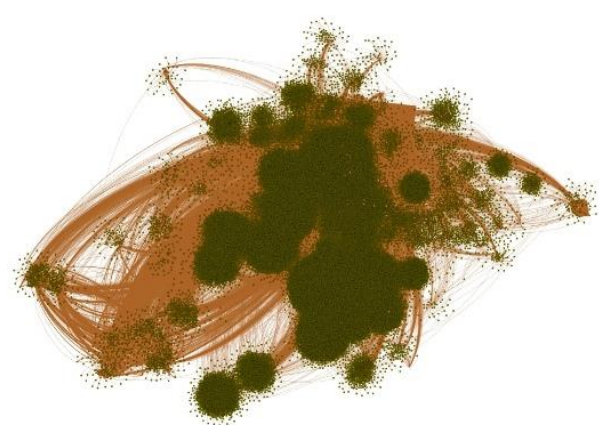

Gambar 4.1. Jaringan Lazada Skala Besar, warna hijau tua mewakili posting kostumer dan coklat mewakili hubungan posting halaman e-commerce.

Sumber: Data diolah Tim Peneliti

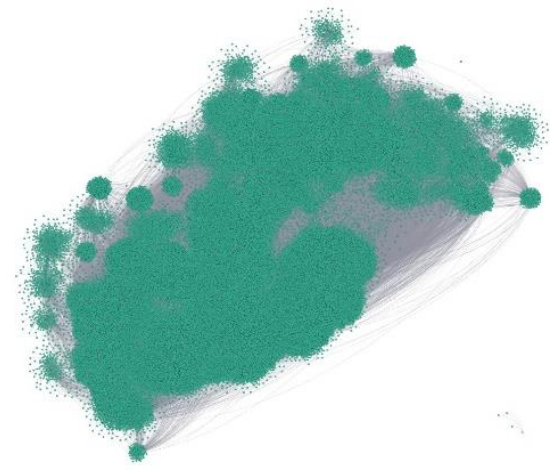

Gambar 4.2. Jaringan Blibli Skala Besar, warna hijau tua mewakili posting kostumer dan warna abu hubungan posting halaman e-commerce.

Sumber: Data diolah Tim Peneliti 


\section{KESIMPULAN}

Interaksi dengan kostumer dan eksistensi sebuah organisasi perusahaan di media sosial menjadi hal yang penting dan terukur. Salah satu cara untuk mengukur interaksi perusahaan dengan pelanggan adalah dengan menghitung sifat jaringan pada topologi jaringan yang terbentuk dari percakapan di media sosial, dalam hal ini Facebook Pages. Strategi konten kreatif dapat mempengaruhi keberhasilan kampanye/kesadaran merek. Ukuran jaringan Lazada yang memiliki ukuran pasar terbesar ternyata memiliki sifat jaringan yang serupa (robustness) dan nilai keterlibatan. Meskipun Blibli tidak lebih besar dalam ukuran pasar mereka namun mereka memiliki performa yang lebih aktif. Properti ini mendukung mekanisme jaringan untuk menarik anggota baru untuk bergabung dalam jaringan. Hal ini menunjukkan bahwa beberapa jenis posting halaman menghasilkan nilai engagement yang lebih tinggi, pola ini bisa menjadi pedoman untuk menumbuhkan ukuran jaringan pasar.

Kami telah menganalisis dua data jaringan pasar berskala besar e-commerce di Indonesia. Jaringan yang dihasilkan dari interaksi sosial memberi kita jalan untuk mengamati proses kompleks yang dinamis dan terlihat berubah secara acak setiap saat, namun sebenarnya mengikuti sifat jaringan sosial yang sama. Praktik pemahaman dalam pasar saat ini didominasi oleh ukuran dan frekuensi. Kumpulan metrik SNA membantu menjelaskan masalah seperti menyebarkan informasi, deteksi komunitas, kekuatan kerapatan, dan beberapa lainnya yang mendukurng keputusan dalam Market Intelegence.

Karena keterbatasan daya perangkat, peneliti tidak dapat melakukan proses yang lebih analitis, sehingga penelitian ini dapat dikembangkan lebih jauh dengan menggunakan perangkat yang lebih kuat dengan menggunakan beberapa pendekatan seperti; 1). Pendekatan untuk proses analisis yang lebih dalam pada deteksi masyarakat 2). Pendekatan dengan memasukkan lebih banyak metrik SNA seperti centrality, global dan lokal clustering, komponen, structural holes 3). Pendekatan dengan memasukkan sifat node dan bobot edge dalam perhitungan metrik. Dengan menggunakan data yang sama dapat membangun model (machine learning) berdasarkan algoritma data mining seperti klasifikasi, clustering, association dan beberapa lainnya untuk memprediksi perilaku pasar.

\section{DAFTAR PUSTAKA}

Barabasi, A.-L. (2012). Network Science. [online]. Available on http://barabasi.com/networksciencebook/ [September 25th, 2017]

C. Chern, A. Lee, J.T. Wei. (2014). Introduction to The Special Issue on Data Analytics for Marketing Intelligence. Springer, 2014.

Evan, Dave. (2010). Social Media Marketing: The Next Generation of Business Engagement. Indianapolis, Indiana: Wiley Publishing, Inc.

K. Seddon, N.C. Skinner, K.C. Postlethwaite. Creating a Model to Examine Motivation for Sustained Engagement in Online Communities. Journal Education and Information Technologies, Volume 12, Issue 1, pp 17-34, 2008 
M. Goldberg, S. Kelley, M.M. Ismail. Communication Dynamics of Blog Network. Advances in Social Network Mining and Analysis and Mining : Second International Workshop, SNAKDD, 2008

Newman, M. (2012). Commmunities, Modules, and Large-Scale Struture in Networks. Nature Physics (8). 25-31.

R. Zheng, Q. Sheng, L. Yao. A Simulation Methods for Social Networks. Journal of Social Network Analysis and Mining, Vol. 5, Issue 14, 2015

Reza, J. I. (2015, 12 1). Ini yang Bikin Shopee Beda dengan Aplikasi Belanja Online Lain. [Online]. Available on Liputan 6: http://tekno.liputan6.com/read/2379358/ini-yang-bikinshopee-beda- dengan-aplikasi-belanja-online-lain [September 28th, 2017].

Stats, I. W. (2017, 06 30). Usage Stats Facebook and Population Statistics. [Online]. [acces on October 25th, 2017]

Wasserman, S., \& Faust, K. (1994). Social Network Analysis: Methods and Applications. Melbourne: Press Syndicate of the University of Cambridge. 